\title{
Physiological Correlates of Sensory Consciousness - Evidence for a Perceptual Awareness Negativity
}

\author{
Cole Dembski, ${ }^{1}$ Christof Koch, ${ }^{2}$ and Michael Pitts ${ }^{1 *}$ \\ ${ }^{1}$ Department of Psychology, Reed College, Portland, OR, USA \\ ${ }^{2}$ Allen Institute for Brain Science, Seattle, WA, USA \\ *Corresponding author. Email: mpitts@reed.edu
}

We critically review the recent literature on six EEG and MEG markers of the neural correlates of consciousness (NCC) for visual, auditory and tactile stimuli in neurotypical volunteers and neurological patients. After ruling out four of these as candidate NCC, we focus on two prominent evoked signals - an early, modality-specific negativity, termed the visual or auditory awareness negativity (VAN and AAN, respectively) and a late, modality-independent positivity termed the $\mathrm{P} 3 \mathrm{~b}$. More than twelve diverse experimental studies found that the P3b is absent despite consciously seeing, hearing, or feeling stimuli, ruling out the P3b as a true NCC. In contrast, no convincing evidence for a dissociation between the awareness negativities and consciousness has been reported thus far. Furthermore, there is evidence for an equivalent signal in the tactile domain, which we term the somatosensory awareness negativity (SAN). These three neural signals are usually maximal on the side of the scalp contralateral to the evoking stimulus, above the associated sensory cortices. We conclude that the data from these three modalities is consistent with a generalized perceptual awareness negativity (PAN) correlated with perceptual consciousness that arises 120-200 ms following stimulus onset and originates from the underlying sensory cortices. The identification of this PAN points towards new, promising avenues for future research and raises an array of concrete questions that can be empirically investigated. 
Introduction For more than half a century, psychologists have taken advantage of the fine temporal resolution of electroencephalography (EEG) and magnetoencephalography (MEG) to track the progression of physiological brain activity related to sensory processing (Sutton et al, 1965; Luck, 2014). Conscious experience fluctuates on a moment-to-moment basis, and the capacity of EEG and MEG to monitor neural responses to a stimulus at the millisecond time scale makes them ideal for investigating the neural correlates of consciousness (NCC), or the minimal neuronal mechanisms jointly sufficient for any one specific conscious experience (Crick \& Koch, 1990; Chalmers, 2000; Koch et al., 2016).

\section{EEG and MEG correlates of consciousness}

As the extant literature on EEG and MEG markers of conscious perception is vast, we here only review recent developments and refer the interested reader to the books by Bachmann (2000), Ögmen \& Breitmeyer (2006), and Dehaene (2014), as well as the comprehensive review by Förster et al. (2020). The present review considers six evoked potentials, five negative going ones and one positivity, linked to consciously seeing, hearing, or feeling stimuli, and considers the extent to which these various potentials are true NCC. We conclude that the existing data is consistent with a generalized and lateralized perceptual awareness negativity that arises $120-200 \mathrm{~ms}$ following stimulus onset, which is likely generated within the underlying sensory cortices.

A diverse set of neural signals accompany conscious perception of a stimulus. However, much of this neural activity does not reflect consciousness per se but rather one or more preceding or subsequent processes such as expectation, attention, memory, judgements, and decision-making (Aru et al., 2012; de Graaf et al., 2012; Tsuchiya et al., 2015). Therefore, once a neural signal has been identified as a potential correlate of consciousness, focused research should try to dissociate consciousness and the proposed NCC in two distinct ways: (1) can the candidate NCC be clearly observed when subjects did not consciously perceive the stimulus; and (2) can a subject consciously perceive a stimulus even when the candidate NCC is absent?

The logic behind this method is straightforward: since a genuine NCC must be present when a stimulus is consciously experienced and absent when the same stimulus is not consciously experienced, a few high-quality experiments demonstrating that a given neural signal is present while consciousness is absent, or vice versa, can definitively rule out the possibility that the neural signal in question is an NCC, even if dozens of studies have reported a correlative relationship between consciousness and that same neural signal.

\section{Dissociations between consciousness and candidate NCC}

Research on the NCC commonly takes one of two broad approaches, targeting either the neuronal mechanisms that determine the content of a specific phenomenal experience (say, seeing a face), known as the content-specific NCC, or the neural substrates that support the ability to have conscious experiences at all regardless of the specific content, the full NCC (Koch et al., 2016). The former typically involves recording neural activity in conscious subjects while presenting stimuli that are sometimes consciously perceived and sometimes not perceived. This can be achieved via the use of threshold detection tasks, masking techniques, and other experimental paradigms such as the attentional blink and change blindness. 
The full NCC are isolated by comparing waking, sleeping, and anesthetized states in healthy volunteers (Koch et al., 2016; Siclari et al., 2017), or observing patients with various disorders of consciousness (DOC) such as coma, unresponsive waking states (UWS; also known as persistent vegetative state), and minimally conscious states (MCS), (Laureys et al., 2010; Chennu \& Bekinschtein, 2012; Ganter et al., 2013; Giacino et al., 2014).

\section{The MMN}

Among the neural signals that have been investigated using these approaches are the mismatch negativity (MMN; Näätänen et al., 2011; Dykstra \& Gutschalk, 2015), a negative-going waveform (roughly 100-300 ms post-stimulus) observed in response to the presentation of a deviant stimulus within an otherwise predictable pattern of stimuli (Näätänen et al., 2011). As this signal can be elicited by auditory as well as visual stimuli, DOC patients and healthy participants in sleeping or anesthetized states can be studied, keeping their eyes closed, while the MMN is recorded.

The results from these experiments are clear: not only does the MMN frequently fail to distinguish between UWS and MCS patients (Fischer et al., 2010; King et al., 2013; Sitt et al., 2014; Wang et al., 2017), it is reliably observed in UWS patients (King et al., 2013; Bekinschtein et al., 2009; King et al., 2013; Sitt et al., 2014; Wang et al., 2017) as well as those in post-anoxic coma (Tzovara et al., 2015). In healthy subjects, the auditory MMN can be evoked across all stages of sleep (Strauss et al., 2015), and the visual MMN can be evoked in fully conscious participants by deviant stimuli that are not consciously perceived (Schlossmacher et al., 2020). Evidently, the MMN can be present when the subject is unconscious of the stimulus - in other words, the MMN and sensory consciousness can be dissociated. Thus, this neural signal cannot be an NCC.

\section{The N400}

The same conclusion has been reached regarding the semantic $\mathbf{N 4 0 0}$ potential (Kiefer, 2002; Rohaut et al., 2015), a negative-going deflection around $400 \mathrm{~ms}$ following stimulus onset characterized by increased amplitude in response to semantically unexpected stimuli (van Gaal et al., 2014). UWS patients display differential N400 responses to semantically incongruent auditory stimuli (Schoenle \& Witzke, 2004; Rohaut et al., 2015), and the N400 can be elicited in healthy individuals by the presentation of semantically incongruent words rendered invisible using different masking techniques as well as during the attentional blink (Luck, Vogel, \& Shapiro, 1996; Kiefer, 2006; Holcomb \& Grainger, 2009; van Gaal et al., 2014; Rohaut et al., 2016). Such demonstrations of a dissociation between the $\mathrm{N} 400$ and consciousness make it clear that the N400 is not a viable NCC.

\section{The N170}

Face stimuli elicit a category-specific negative waveform with a peak latency of $170 \mathrm{~ms}$, known as the N170 (Pegna et al., 2008; Navajas et al., 2013; Sandberg et al., 2013). This neural signal has been observed even when face stimuli are fully suppressed from consciousness using continuous flash suppression (Sterzer et al., 2009; Suzuki \& Noguchi, 2013) or the attentional blink (Harris et al., 2013). Further confirmation that the N170 can be dissociated from consciousness comes from the case study of R.F.S, a man with selective metamorphopsia unable to identify the digits 2-9 and 
any visual stimuli embedded in these digits (Schubert et al., 2020). R.F.S could not discriminate between faces and scrambled-faces when they were presented within supersized digits 2-9, but still displayed a robust face-specific N170. Clearly, the N170 can be evoked by face stimuli in the absence of conscious perception across a variety of different circumstances, thus ruling it out as an NCC.

\section{The N2pc}

The N2 posterior-contralateral potential, known as the N2pc (Woodman \& Luck, 2003; Travis et al., 2019), reflects the allocation of spatial attention and is measured at posterior locations contralateral to the attended stimulus in the 200-300 ms time range (Schankin et al., 2009). Research on the N2pc has resulted in a nuanced array of evidence, likely due in part to the complex relationship between attention and consciousness (Tsuchiya \& Koch, 2007; Cohen et al., 2012; Pitts et al., 2018; Nani et al., 2019). While the use of certain masking techniques may eliminate the N2pc, other methods of masking still allow for an N2pc to be evoked, despite participants not consciously seeing the target (Woodman and Luck, 2003; Robitaille \& Jolicoeur, 2006). Familiarity can also play a role in determining whether an N2pc occurs outside of conscious perception: Bola et al. (2020) observed an N2pc in response to masked face stimuli, but only when the face in question was familiar to the observer. Further complicating matters, while N2pc magnitude is often greater when the inducing stimulus is consciously perceived (Verleger \& Jaskowski, 2008; Schankin et al., 2009), this may only hold when the stimulus is task-relevant (Travis et al., 2019). Nevertheless, though heavily influenced by specific conditions, the N2pc is frequently present in the absence of conscious perception and can therefore be excluded as a candidate NCC.

\section{The P3b}

The P300, a positive-going ERP wave with a latency of approximately 250-600 ms, is composed of at least two distinct sub-components, an earlier fronto-central P3a and a later, parietallymaximal P3b (Polich, 2007; Barry et al., 2020; Fig. 1). The P3a occurs in states of unconsciousness and reflects automatic, stimulus-driven attentional processes, such as when an unexpected stimulus captures one's attention involuntarily (Polich, 2007; Chennu \& Bekinschtein, 2012). In contrast, the $\mathrm{P} 3 \mathrm{~b}$ remains the subject of much debate regarding its functional significance (Polich, 2020). Most often elicited in experimental settings during tasks that involve discriminating infrequent or 'oddball' targets, the P3b has been hypothesized to reflect storage of content in working memory, stimulus-response transformations, context updating, stimulus categorization, and - the subject of this review - conscious perception (Sergent et al., 2005; Dehaene \& Changeux, 2011; Luck, 2014; Verleger, 2020). Note that in such oddball paradigms, the P3b is observed only in response to the consciously detected deviant stimulus and not to the standard stimuli (which are presumably also consciously detected), contrary to what would be expected from an NCC, which should be evoked by all consciously detected stimuli, regardless of their probability.

Even so, based on the multiplicity of studies that have observed a P3b only under conscious conditions (e.g. Koivisto et al., 2005; Sergent et al., 2005; Babiloni et al., 2006; Del Cul et al., 2007; Koivisto et al., 2008; Salti et al., 2012; Wyart et al, 2012; Auksztulewicz \& Blankenburg, 2013; Rutiku et al., 2015; Dykstra et al., 2016; Eklund \& Wiens, 2019), the P3b is widely considered to be the most reliable and promising NCC (Dehaene \& Changeux, 2011; Dehaene, 
2014; Naccache et al., 2016), though its relationship to consciousness has been discussed with more nuance in recent years, even by the most prominent proponents of this view (Mashour et al., 2020). In particular, the $\mathrm{P} 3 \mathrm{~b}$ is proposed to index a nonlinear amplification or "ignition" of cortical activity throughout a distributed "global neuronal workspace" involving fronto-parietal areas (Del Cul et al., 2007; Dehaene \& Changeux, 2011; Dehaene, 2014). An opposing camp argues that the $\mathrm{P} 3 \mathrm{~b}$ is, instead, reflective of post-perceptual processing and not consciousness per se (Förster et al., 2020). Here, we concentrate on assessing the robustness of the available empirical evidence for a dissociation between the P3b and consciousness, setting aside for now any potential links to theoretical models.

There is variability in the terminology referring to the P3b, which can include 'P3' or ' $\mathrm{P} 300$ ' (Luck, 2014); in addition, some have adopted the term 'late positivity' (LP) to refer specifically to the difference in P3b amplitude between conscious vs. unconscious conditions (Förster et al., 2020). Accordingly, papers that use the terms "LP" or "P3/P300" in their reporting are considered here if the relevant signal has the characteristics of the $\mathrm{P} 3 \mathrm{~b}$.

Stimuli from multiple sensory modalities can elicit a P3b, and DOC studies in patients using auditory tones have reported a correlative relationship between the P3b and consciousness (Faugeras et al., 2011; Li et al., 2015). However, while P3b activity reliably differentiates healthy control participants from DOC patients, it often fails to distinguish between UWS, MCS, and conscious-but-impaired patients (Perrin et al., 2006; Sitt et al., 2014). In fact, the P3b may not be elicited at all in many MCS and conscious DOC patients, even under conditions that elicit a robust P3b in controls (Fischer et al., 2010; Sitt et al., 2014). Ignoring the lack of a P3b response in MCS patients - and even more so in the conscious DOC patients studied by Sitt et al. (2014) - risks ignoring the critical difference between conscious and unconscious patients.

Caution must be taken when considering DOC studies, especially since there is greater variability in the latency and topography of the P3b in these patients, above and beyond the substantial variability already observed in healthy controls (King et al., 2013; Rutiku et al., 2016). However, the P3b tends to be robust to the statistical effects of such variability, remaining significant despite wide variations in amplitude and latency (Rutiku et al., 2016). This makes the notable failure of Fischer et al. (2010) to elicit a P3b in 10 of 11 MCS patients even more striking, as well as the lack of a significant P3b across 68 recordings from MCS patients and 24 recordings from conscious DOC patients reported by Sitt et al. (2014) - who did, in contrast, find a highly significant P3b in their control group of 14 healthy volunteers. These studies casts significant doubt on the hypothesis that the $\mathrm{P} 3 \mathrm{~b}$ is an NCC.

A growing number of studies with neurotypical participants describe dissociations between stimulus consciousness and the P3b. Melloni et al. (2011) found that the P3b tracks stimulus visibility prior to the formation of expectations about the stimuli but ceases to distinguish between seen and unseen stimuli once expectations have been formed. Furthermore, the P3b correlates with perceptual consciousness during tasks that engage higher-level cognitive processes (e.g., evaluating the magnitude of masked digits), but not during lower-level tasks (e.g., discriminating the color of masked digits; Derda et al., 2019). Similarly, identification but not detection of changes in change-blindness paradigms correlates with the P3b (Busch et al., 2010; Sekar et al., 2013). Crucially, recent evidence has indicated that this effect may be ultimately reflective of the 
requirements of the task, not the specific process of identification itself: instead, depending on the task at hand, the $\mathrm{P} 3 \mathrm{~b}$ may at times reflect conscious detection, at times conscious identification, or both (Koivisto et al., 2017).

Studies manipulating the task-relevance of stimuli have proven to be insightful for distinguishing the genuine NCC from post-perceptual processes (Aru et al., 2012). Using either traditional masking or inattentional blindness to manipulate stimulus visibility while separately controlling task requirements, numerous studies over the last decade found that the P3b is only present when stimuli are task-relevant (Pitts et al., 2012, 2014a, 2014b; Shafto \& Pitts, 2015; Schelonka et al., 2017; Cohen et al., 2020; Schlossmacher et al., 2020). Recent work in the auditory and somatosensory domains has produced the same results regarding the P3b: only when stimuli are task-relevant do they evoke a P3b, and only then does the P3b correlate with conscious perception (Schröder et al., 2020; Schlossmascher et al., 2021). Schlossmacher et al. (2021) used an inattentional deafness paradigm that paralleled the inattentional blindness paradigms used by Schlossmacher et al. (2020) and preceding studies, and their results were consistent across visual and auditory modalities: regardless of participants' stimulus awareness or lack thereof, the P3b only reflected consciousness when the stimulus was task-relevant.

Schröder et al. (2020) compared neural activity during a standard tactile detection task and a tactile-visual matching task - the latter intended to dissociate stimulus detection per se from the task requirements - while keeping stimulus characteristics the same. Only when stimulus detection was the primary task did the P3b correlate with consciousness; in the matching task, when both the presence and the absence of the stimulus were equally task-relevant and equally meaningful, the P3b no longer had any correlation with conscious perception.

This evidence indicates that the $\mathrm{P} 3 \mathrm{~b}$ is reflective of post-perceptual and task-related processes, not conscious perception, and neatly explains the above mentioned finding that the P3b is only elicited by deviant stimuli in oddball paradigms: once a pattern has been established, the deviant stimulus is the target relevant to the task, while the standard stimuli are effectively distractors.

Note that the type of dissociation between the P3b and consciousness is distinct from that of the four neural signals previously discussed: while the MMN, N400, N170, and N2pc can be present in the absence of consciousness, the reverse is true of the $\mathrm{P} 3 \mathrm{~b}$ - it can be absent despite the presence of consciousness (Table 1). A few case studies (Cavinato et al., 2012; Schubert et al., 2020) and experiments with neurotypical participants have offered some preliminary indications that the P3b may be evoked in the absence of consciousness (Silverstein et al., 2016; Doradzińska et al., 2020), but there remains some debate regarding the validity and replicability of such studies (e.g. Naccache et al., 2016).

\begin{tabular}{|l|c|c|c|c|c|}
\hline & MMN & N170 & N2pc & P3b & N400 \\
\hline $\begin{array}{l}\text { Present w/out } \\
\text { consciousness }\end{array}$ & $\checkmark$ & $\checkmark$ & $\checkmark$ & $?$ & $\checkmark$ \\
\hline $\begin{array}{l}\text { Absent with } \\
\text { consciousness }\end{array}$ & - & - & - & $\checkmark$ & - \\
\hline
\end{tabular}

Table 1. Dissociations between consciousness and proposed event-related markers. 
The diverse research discussed here, employing a multitude of distinct methods, consistently reports a clear absence of a P3b despite the subject consciously perceiving the stimulus; these repeated demonstrations of a dissociation make it clear that the P3b cannot be an NCC.

\section{Visual and auditory awareness negativity}

Negative-going EEG signals in the 100-300 ms time range have been repeatedly observed to correlate with consciousness in the visual and, more recently, auditory modalities while being unaffected by task requirements or response conditions (Koivisto \& Revonsuo, 2003; Gutschalk et al., 2008; Eklund \& Wiens, 2019; Eklund et al., 2019; Ye \& Lyu, 2019;). Referred to as the visual awareness negativity (VAN) and auditory awareness negativity (AAN), these signals are isolated by calculating the negative amplitude difference in neural signals between consciously perceived and non-perceived stimuli during the 100-300 ms time range (see Fig. 1; Eklund et al., 2020a; Förster et al., 2020). The VAN is maximal over posterior regions (Koivisto \& Grassini, 2016) and the AAN at more anterior scalp sites (Eklund \& Wiens, 2019). The magnitudes of both are largest over regions contralateral to the inducing stimulus (Koivisto \& Grassini, 2016; Eklund \& Wiens, 2018; Harris et al., 2018; Eklund et al., 2020b). This is compatible with the idea that these potentials reflect activity in early and/or mid-level, topographically organized visual and auditory cortical regions.

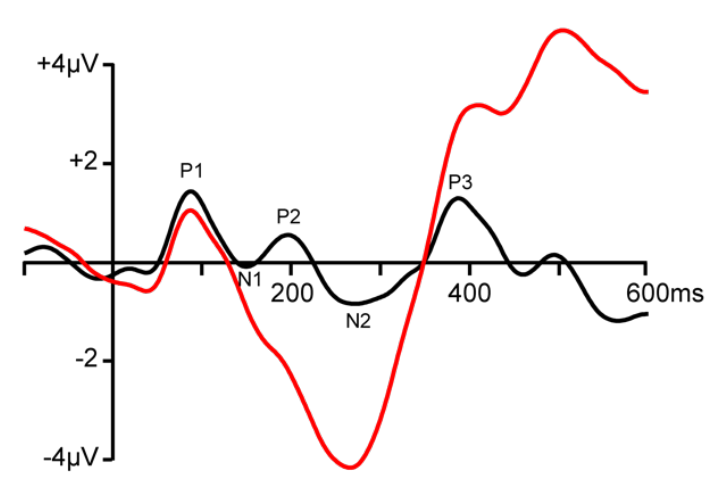

Conscious Perception \& Report

Unconscious Processing

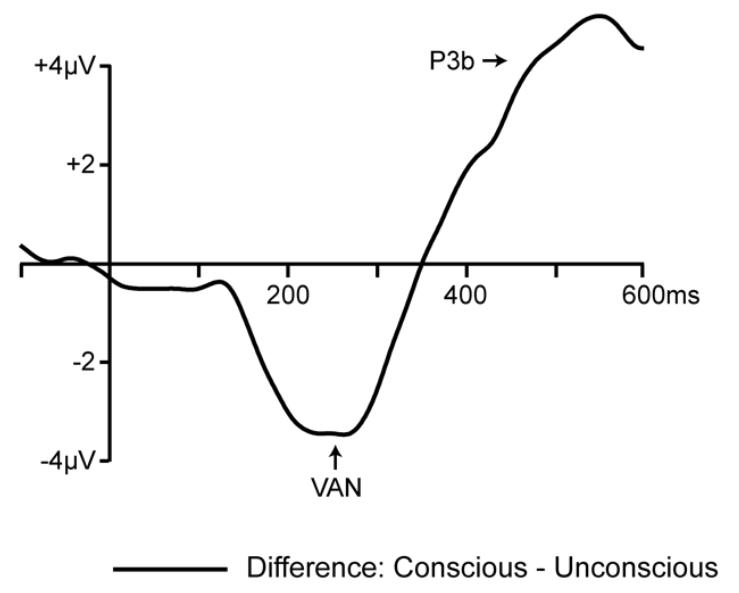

Figure 1. Two electrophysiological candidate correlates of visual consciousness. Left: Timecourse of neural signals recorded from electrodes at occipital-parietal scalp locations (here, PO8), time-locked to the onset of a visual stimulus that was or was not consciously perceived. Right: Difference wave created by subtracting the unconscious from the conscious condition. This reveals both a VAN as well as a P3b. This grand-averaged data $(\mathrm{N}=16)$ is re-plotted from

Shafto \& Pitts (2015), with the red trace depicting a condition in which a face stimulus was consciously seen and task relevant and the black trace depicting a condition in which the same face stimulus was unconsciously processed due to inattentional blindness.

Like the P3b, the VAN and AAN have been linked to theoretical frameworks for consciousness and are often cited as support for models that emphasize the importance of early recurrent processing to consciousness (Koch et al., 2016; Lamme et al., 2018; Eklund et al., 2020; Förster 
et al., 2020). Again, however, our purpose here is to assess the promise of these neural signals as potential NCC, rather than attempt to link them to larger theories.

The VAN has been studied much more extensively than the AAN, and most evidence has firmly supported the hypothesis that the VAN is an NCC (e.g. Koivisto \& Revonsuo, 2003; Ojanen et al., 2003; Wilenius-Emet et al., 2004; Sergent et al., 2005; Koivisto et al., 2007; Liu et al., 2012; Pitts et al., 2014; Tagliabue et al., 2016; Eklund \& Wiens, 2018; Ye et al., 2019; Mazzi et al., 2020).

Six studies, though, have failed to observe a VAN under conditions where it should be expected. Upon review, however, these experiments suffer from a few critical problems, the most common being a failure to account for the spatial lateralization of VAN topography. Five used target stimuli that were lateralized to one hemifield, but the authors failed to consider the lateralization of the VAN during data analysis by processing signals from both hemispheres (Babiloni et al., 2006; Lamy et al., 2008; Salti et al., 2012; Boncompte \& Cosmelli, 2018; Scrivener et al., 2019). Subsequent studies closely following the procedures of Lamy et al. (2008) and Salti et al. (2012) while controlling for lateralization in their analyses did observe a VAN (Koivisto \& Grassini, 2016; Eklund \& Wiens, 2018). Thus, we discount these putative failures to confirm a VAN.

The multiplicity of electrophysiological components that can occur during the VAN time range, including the N170 and N2pc, adds an additional complication to isolating and identifying the VAN (Förster et al., 2020). For example, Boncompte \& Cosmelli (2018) failed to detect a bilateral VAN for lateralized moving stimuli; however, while analyzing contralateral vs. ipsilateral activity to measure the N2pc, they did, in fact, find a significant negative difference correlating with conscious motion perception in the $200-300 \mathrm{~ms}$ time - but only at electrode sites contralateral to the moving stimulus. Had they specifically calculated the difference in neural activity between conscious and unconscious trials for contralateral electrodes only, a significant VAN would have been found (Fig. 2).
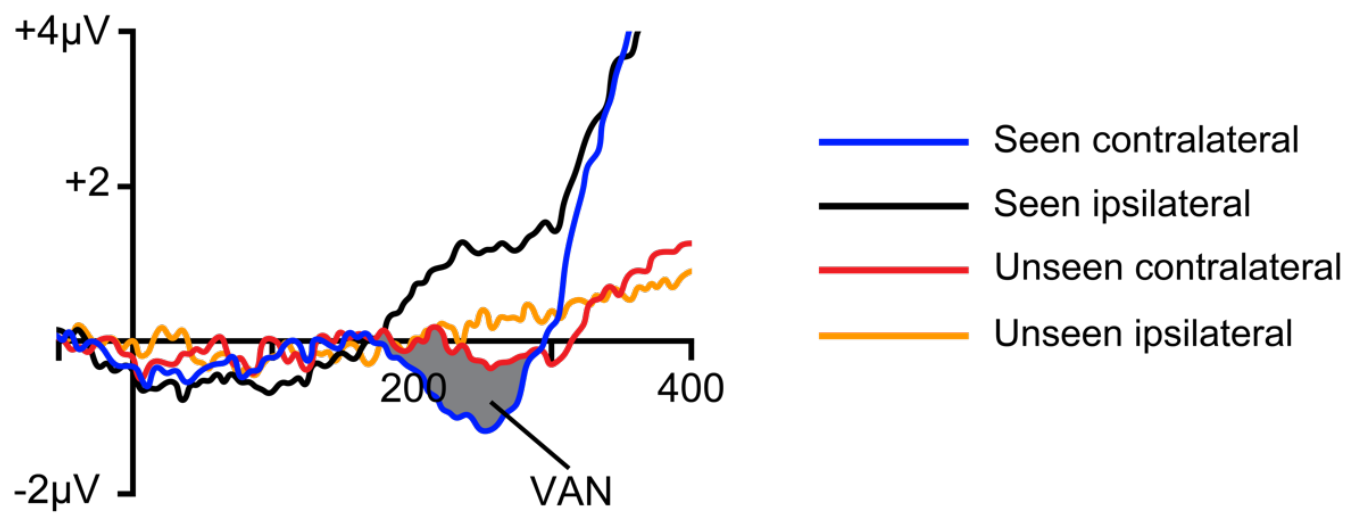

Figure 2. ERP waveforms evoked by contralateral vs. ipsilateral visual stimuli in

Boncompte \& Cosmelli (2018). While no significant difference in activity between contralateral and ipsilateral stimuli was present when the lateralized visual stimuli were not seen, a significant negative difference (i.e. VAN) emerges between the seen- and unseen-contralateral conditions (blue vs. red waveform, 200-300 ms). Pooling contralateral and ipsilateral data cancels out this seen-unseen difference. Adapted from Boncompte \& Cosmelli, 2018 (Fig. 4a). 
In the single study using non-lateralized stimuli that failed to observe a VAN, Babiloni et al. (2010) reported that an 'N170' correlated with awareness of faces, while the VAN was absent. However, the authors used only face stimuli in their paradigm, making it difficult to isolate the N170, which is defined as a difference between face and non-face stimuli (Eimer, 2011). Instead, they analyzed the difference between seen versus unseen faces in the N170 time range - meaning that the resulting neural difference could have contained an N170, a VAN, or a combination of both.

Though it must be acknowledged that research on the AAN is scarce, only a single study investigating the AAN failed to detect it. Giani et al. (2015) employed a complex design in which participants had to detect a target that was defined as a sequence of two repeated tones within a multi-tone background. They observed an AAN-like negativity that correlated with awareness only in response to the second tone in the target pair, but not the first, which the authors interpret as being indicative of the 'AAN' reflecting the process of segregating an auditory stimulus from a multi-tone background rather than consciously perceiving the stimulus. Critically, however, the target could be consciously identified only after both tones had been played. Accordingly, no neural activity related to target detection should be observed for the first tone, because, while perception of the first tone is a prerequisite for target detection, it is not sufficient. As such, the findings of Giani et al. (2015) cannot be considered firm evidence against the AAN being a true NCC.

Taken together, the studies discussed above that reported an absence of VAN or AAN when contrasting neural signals elicited by perceived versus not-perceived stimuli fail to present a significant challenge to the hypothesis that the VAN and AAN are true NCC. As such, these neural signals remain the most promising neural correlates of conscious perception to date.

\section{The awareness negativity: A general marker of conscious perception?}

The identification of similar markers of consciously seeing and hearing begs the question of whether analogous neural signals might correlate with stimulus consciousness in other modalities. Indeed, mounting evidence indicates the existence of a somatosensory counterpart to the VAN/AAN known as the N140, here referred to as the somatosensory awareness negativity (SAN). The SAN is a negative-going somatosensory evoked potential with a peak latency of approximately 120-180 ms, a fronto-central topography contralateral to the stimulated body part (Auksztulewicz et al., 2012; Auksztulewicz \& Blankenburg, 2013; Al et al., 2020; Forschack et al., 2020; Schröder et al., 2020), and, like the VAN and AAN, is robust to task manipulations (Kida et al., 2012). 
The VAN, AAN, and SAN share a striking number of similarities, including their latency, polarity, and lateralization, raising the possibility that similar neural processes may support consciousness across different modalities (Fig. 3 and Table 2). Though their topographies are distinct - the VAN is maximal over posterior, occipital-parietal areas (Koivisto \& Revonsuo, 2017; Eklund \& Wiens, 2018), while the AAN and SAN are strongest over more anterior, central regions (Auksztulewicz et al., 2012; Eklund \& Wiens, 2019) - they match the expected topographies of signals originating from their respective sensory cortical areas.
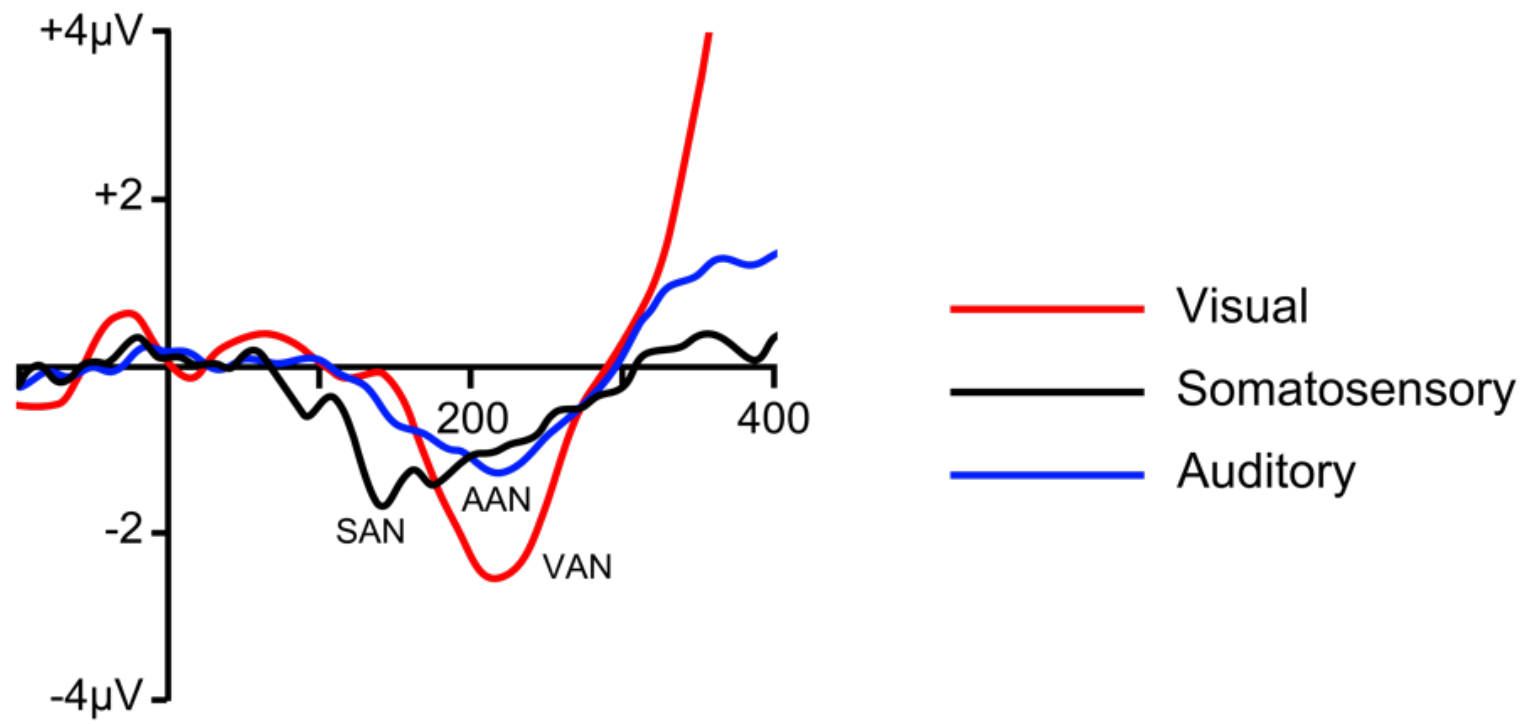

Figure 3. Visual, auditory, and somatosensory awareness negativities. Difference waves between conscious and unconscious trials in detection tasks using visual, auditory, or somatosensory stimuli, recorded from the maximal scalp site(s) for each respective sensory modality (VAN: averaged over occipital electrodes; AAN: averaged across Fz and Cz electrodes; SAN: electrode C6). Waveforms are based on Koivisto \& Revonsuo, 2003, Fig. 3(O) (VAN); Eklund \& Wiens, 2019, Fig. 3a (AAN); Auksztulewicz et al., 2012, Fig. 2 b (SAN).

Indeed, source localization, complemented by structural and functional MRI data, implicate the sensory cortices as the primary generators of the three neural signals: the VAN has been consistently localized to occipital and inferotemporal regions, corresponding to low and mid-level visual cortices within the 'ventral visual stream' (Liu et al., 2012; Pitts et al., 2012; Sandberg et al., 2014; Andersen et al., 2016; Babiloni et al., 2016; Tagliabue et al., 2016); the AAN from the auditory cortex and surrounding regions (Wiegand \& Gutschalk, 2012; Eklund et al., 2019); and the SAN from the primary and secondary somatosensory cortices (Jones, 2007; Auksztulewicz \& Blankenburg, 2013; Hämäläinen et al., 2014; Schröder et al., 2019). Strikingly, neural activity associated with consciousness in these regions follows similar enough patterns that decoders trained on data from one of the three modalities (visual, auditory, or tactile) can successfully predict conscious perception when applied to another (Sanchez et al., 2019). Finally, the VAN, AAN, and SAN are conspicuously absent or highly attenuated in right brain-damaged patients who are unable to perceive stimuli in the left hemifield due to multimodal hemi-spatial neglect; furthermore, these neural signals reappear and normalize as symptoms in the corresponding modality improve (Hämäläinen et al., 2014). 
These converging findings point to the existence of a generalized but modality-specific electrophysiological marker of sensory consciousness, robust to variation in task relevance or response requirements: a generalized "perceptual awareness negativity" (PAN), a negativegoing neural signal beginning between 120-200 ms following the onset of a consciously perceived visual, auditory, or tactile stimulus (Table 2).

\begin{tabular}{|l|c|c|c|}
\hline & VAN & AAN & SAN \\
\hline Time window & $170-290 \mathrm{~ms}$ & $130-230 \mathrm{~ms}$ & $125-180 \mathrm{~ms}$ \\
\hline Average peak latency & $230 \mathrm{~ms}$ & $180 \mathrm{~ms}$ & $140 \mathrm{~ms}$ \\
\hline Topography & Occipital & Fronto-central & Fronto-central \\
\hline
\end{tabular}

Table 2. Latencies and topographies of the VAN, AAN, and SAN. Data are derived from 16 VAN, 10 AAN, and 6 SAN published studies. See supplementary materials.

This suggests that similar processes might underly consciousness across sensory domains, with unique cortical sources depending on the modality. If so, these common mechanisms might be isolated from modality-specific processes to reveal generalized patterns of neural activity related to perceptual consciousness across sensory domains. Future research employing both non-invasive EEG and MEG in humans as well as invasive techniques in animals and human patients undergoing neurosurgery will be necessary to identify the anatomical and cellular mechanisms responsible for generating the PAN (Siegle et al., 2021), identify its cellular constituents, pursue its neuronal sequela, and address a host of associated questions (Box 1). 


\section{Box 1. Outstanding questions}

Does the PAN extend to olfaction, gustation, interoceptive sensations, and pain?

Does the PAN correlate on a trial-to-trial level, and not just on average, with stimulus consciousness?

How do stimulus salience (e.g., stimulus energy, contrast), stimulus duration, location in visual, auditory and body-space, and category (low-level, such as oriented lines or gratings, vs. highlevel, such as words and faces, for visual stimuli) affect the latency, topography, and amplitude of the PAN?

How do expectations and task-relevance modulate the PAN?

Can the PAN be elicited by by-passing peripheral receptors, e.g. by direct brain stimulation, by recall or imagery, or during dreams?

How does selective attention (and the associated negativities) modulate the PAN?

Can a standard paradigm for eliciting the PAN be developed for use in patients with disorders of consciousness?

What is the significance of the PAN to multimodal integration, binding, and other cross-modal interactions?

Does the PAN originate in primary or in higher-order sensory cortical regions? Does it depend on input from pre-frontal regions?

Can the PAN be elicited in either hemisphere of split-brain patients?

\section{Acknowledgements}

This project was made possible, in part, through the support of grants from Templeton World Charity Foundation Inc. (TWCF0389), the National Science Foundation (BCS-1829470) and the Tiny Blue Dot Foundation. The opinions expressed in this publication are those of the authors and do not necessarily reflect the views of Templeton World Charity Foundation, Inc., or the National Science Foundation. The work of CK was supported by the Allen Institute. We thank the Allen Institute founder, Paul G. Allen, for his vision, encouragement, and support. 


\section{References}

Al, E., Iliopoulos, F., Forschack, N., Nierhaus, T., Grund, M., Motyka, P., Gaebler, M., Nikulin, V. V., \& Villringer, A. (2020). Heart-brain interactions shape somatosensory perception and evoked potentials. Proceedings of the National Academy of Sciences, 117(19), 10575-10584.

Andersen, L. M., Pedersen, M. N., Sandberg, K., \& Overgaard, M. (2016). Occipital MEG activity in the early time range $(<300 \mathrm{~ms})$ predicts graded changes in perceptual consciousness. Cerebral Cortex, 26(6), 2677-2688.

Aru, J., Bachmann, T., Singer, W., \& Melloni, L. (2012). Distilling the neural correlates of consciousness. Neuroscience \& Biobehavioral Reviews, 36(2), 737-746.

Auksztulewicz, R., \& Blankenburg, F. (2013). Subjective rating of weak tactile stimuli is parametrically encoded in event-related potentials. Journal of Neuroscience, 33(29), 11878 11887.

Auksztulewicz, R., Spitzer, B., \& Blankenburg, F. (2012). Recurrent neural processing and somatosensory awareness. Journal of Neuroscience, 32(3), 799-805.

Babiloni, C., Marzano, N., Soricelli, A., Cordone, S., Millán-Calenti, J. C., Del Percio, C., \& Buján, A. (2016). Cortical neural synchronization underlies primary visual consciousness of qualia: Evidence from event-related potentials. Frontiers in Human Neuroscience, 10.

Babiloni, C., Vecchio, F., Buffo, P., Buttiglione, M., Cibelli, G., \& Rossini, P. M. (2010). Cortical responses to consciousness of schematic emotional facial expressions: A highresolution EEG study. Human Brain Mapping, 31(10), 1556-1569.

Babiloni, C., Vecchio, F., Miriello, M., Romani, G. L., \& Rossini, P. M. (2006). Visuo-spatial consciousness and parieto-occipital areas: A high-resolution EEG study. Cerebral Cortex, $16(1), 37-46$.

Bachmann, T. (2000). Microgenetic Approach to the Conscious Mind. John Benjamins Publishing Company.

Barry, R. J., Steiner, G. Z., Blasio, F. M. D., Fogarty, J. S., Karamacoska, D., \& MacDonald, B. (2020). Components in the P300: Don't forget the Novelty P3! Psychophysiology, 57(7), e13371.

Bekinschtein, T. A., Dehaene, S., Rohaut, B., Tadel, F., Cohen, L., \& Naccache, L. (2009). Neural signature of the conscious processing of auditory regularities. Proceedings of the National Academy of Sciences of the United States of America, 106(5), 1672-1677.

Bola, M., Paź, M., Doradzińska, Ł., \& Nowicka, A. (2020). The self-face captures attention without consciousness: Evidence from the N2pc ERP component analysis. BioRxiv, 2020.01.22.915595. 
Boncompte, G., \& Cosmelli, D. (2018). Neural correlates of conscious motion perception. Frontiers in Human Neuroscience, 12.

Busch, N. A., Fründ, I., \& Herrmann, C. S. (2010). Electrophysiological evidence for different types of change detection and change blindness. Journal of Cognitive Neuroscience, 22(8), 1852-1869.

Cavinato, M., Rigon, J., Volpato, C., Semenza, C., \& Piccione, F. (2012). Preservation of auditory P300-like potentials in cortical deafness. PLoS ONE, 7(1), e29909.

Chalmers, D. (2000). What is a neural correlate of consciousness? In T. Metzinger (Ed.), Neural Correlates of Consciousness: Conceptual and Empirical Questions (pp. 17-39). MIT Press.

Chennu, S., \& Bekinschtein, T. A. (2012). Arousal modulates auditory attention and awareness: Insights from sleep, sedation, and disorders of consciousness. Frontiers in Psychology, 3.

Cohen, M. A., Ortego, K., Kyroudis, A., \& Pitts, M. (2020). Distinguishing the neural correlates of perceptual awareness and postperceptual processing. Journal of Neuroscience, 40(25), 4925-4935.

Crick, F., \& Koch, C. (1990). Towards a neurobiological theory of consciousness. Seminars in the Neurosciences, 2, 263-275.

de Graaf, T. A., Hsieh, P.-J., \& Sack, A. T. (2012). The 'correlates' in neural correlates of consciousness. Neuroscience \& Biobehavioral Reviews, 36(1), 191-197.

Dehaene, S. (2014). Consciousness and the brain: Deciphering how the brain codes our thoughts. Viking.

Dehaene, S., \& Changeux, J.-P. (2011). Experimental and theoretical approaches to conscious processing. Neuron, 70(2), 200-227.

Del Cul, A., Baillet, S., \& Dehaene, S. (2007). Brain dynamics underlying the nonlinear threshold for access to consciousness. Plos Biology, 5(10), 2408-2423.

Derda, M., Koculak, M., Windey, B., Gociewicz, K., Wierzchoń, M., Cleeremans, A., \& Binder, M. (2019). The role of levels of processing in disentangling the ERP signatures of conscious visual processing. Consciousness and Cognition, 73, 102767.

Doradzińska, Ł., Wójcik, M. J., Paź, M., Nowicka, M. M., Nowicka, A., \& Bola, M. (2020). Unconscious perception of one's own name modulates amplitude of the P3b ERP component. Neuropsychologia, 147, 107564.

Dykstra, A. R., \& Gutschalk, A. (2015). Does the mismatch negativity operate on a consciously accessible memory trace? Science Advances, 1(10), e1500677. 
Eimer, M. (2011). The face-sensitive N170 component of the event-related brain potential. In A. J. Calder, G. Rhodes, M. H. Johnson, \& J. V. Haxby (Eds.), Oxford Handbook of Face Perception (pp. 430-449). Oxford University Press.

Eklund, R., Gerdfeldter, B., \& Wiens, S. (2019). Effects of a manual response requirement on early and late correlates of auditory awareness. Frontiers in Psychology, 10, 102954.

Eklund, R., Gerdfeldter, B., \& Wiens, S. (2020a). Is auditory awareness negativity confounded by performance? Consciousness and Cognition, 83 .

Eklund, R., Gerdfeldter, B., \& Wiens, S. (2020b). The early but not the late neural correlate of auditory awareness is contralateral to auditory stimulation. PsyArXiv.

Eklund, R., \& Wiens, S. (2018). Visual awareness negativity is an early neural correlate of awareness: A preregistered study with two Gabor sizes. Cognitive, Affective \& Behavioral Neuroscience, 18(1), 176-188.

Eklund, R., \& Wiens, S. (2019). Auditory awareness negativity is an electrophysiological correlate of awareness in an auditory threshold task. Consciousness and Cognition, 71, 7078.

Faugeras, F., Rohaut, B., Weiss, N., Bekinschtein, T. A., Galanaud, D., Puybasset, L., Bolgert, F., Sergent, C., Cohen, L., Dehaene, S., \& Naccache, L. (2011). Probing consciousness with event-related potentials in the vegetative state. Neurology, 77(3), 264-268.

Fischer, C., Luaute, J., \& Morlet, D. (2010). Event-related potentials (MMN and novelty P3) in permanent vegetative or minimally conscious states. Clinical Neurophysiology, 121(7), 1032-1042.

Forschack, N., Nierhaus, T., Müller, M. M., \& Villringer, A. (2020). Dissociable neural correlates of stimulation intensity and detection in somatosensation. NeuroImage, 217.

Förster, J., Koivisto, M., \& Revonsuo, A. (2020). ERP and MEG correlates of visual consciousness: The second decade. Consciousness and Cognition, 80.

Gantner, I. S., Bodart, O., Laureys, S., \& Demertzi, A. (2013). Our rapidly changing understanding of acute and chronic disorders of consciousness: Challenges for neurologists. Future Neurology, 8(1), 43-54.

Giacino, J. T., Fins, J. J., Laureys, S., \& Schiff, N. D. (2014). Disorders of consciousness after acquired brain injury: The state of the science. Nature Reviews Neurology, 10(2), 99-114.

Giani, A. S., Belardinelli, P., Ortiz, E., Kleiner, M., \& Noppeney, U. (2015). Detecting tones in complex auditory scenes. NeuroImage, 122, 203-213.

Gutschalk, A., Micheyl, C., \& Oxenham, A. J. (2008). Neural correlates of auditory perceptual awareness under informational masking. PLOS Biology, 6(6), e138. 
Hämäläinen, H., Kwon, M. S., Lindell, A., Jalas, M., Torsti, J., \& Tenovuo, O. (2014). Neglect is a spatial failure of alerting mechanisms required for awareness: An ERP study. Journal of Basic and Applied Sciences, 10(0), 239-256.

Harris, A. M., Dux, P. E., \& Mattingley, J. B. (2018). Awareness is related to reduced poststimulus alpha power: A no-report inattentional blindness study. European Journal of Neuroscience, 54, 4111-4422.

Harris, J. A., McMahon, A. R., \& Woldorff, M. G. (2013). Disruption of visual awareness during the attentional blink is reflected by selective disruption of late-stage neural processing. Journal of Cognitive Neuroscience, 25(11), 1863-1874.

Holcomb, P. J., \& Grainger, J. (2009). ERP effects of short interval masked associative and repetition priming. Journal of Neurolinguistics, 22(3), 301-312.

Jones, S. R., Pritchett, D. L., Stufflebeam, S. M., Hämäläinen, M., \& Moore, C. I. (2007). Neural correlates of tactile detection: A combined magnetoencephalography and biophysically based computational modeling study. The Journal of Neuroscience: The Official Journal of the Society for Neuroscience, 27(40), 10751-10764.

Kida, T., Kaneda, T., \& Nishihira, Y. (2012). Modulation of somatosensory processing in dual tasks: An event-related brain potential study. Experimental Brain Research, 216(4), 575-584.

Kiefer, M. (2002). The N400 is modulated by unconsciously perceived masked words: Further evidence for an automatic spreading activation account of N400 priming effects. Cognitive Brain Research, 13(1), 27-39.

King, J. R., Faugeras, F., Gramfort, A., Schurger, A., El Karoui, I., Sitt, J. D., Rohaut, B., Wacongne, C., Labyt, E., Bekinschtein, T., Cohen, L., Naccache, L., \& Dehaene, S. (2013). Single-trial decoding of auditory novelty responses facilitates the detection of residual consciousness. NeuroImage, 83, 726-738.

Koch, C., Massimini, M., Boly, M., \& Tononi, G. (2016). Neural correlates of consciousness: Progress and problems. Nature Reviews Neuroscience, 17(5), 307-321.

Koch, C. \& Tsuchiya, N. (2007). Attention and consciousness: Two distinct brain processes. Trends in Cognitive Sciences, 11, 16-22.

Koivisto, M., \& Grassini, S. (2016). Neural processing around $200 \mathrm{~ms}$ after stimulus-onset correlates with subjective visual awareness. Neuropsychologia, 84, 235-243.

Koivisto, M., Grassini, S., Salminen-Vaparanta, N., \& Revonsuo, A. (2017). Different electrophysiological correlates of visual awareness for detection and identification. Journal of Cognitive Neuroscience, 29(9), 1621-1631.

Koivisto, M., \& Revonsuo, A. (2003). An ERP study of change detection, change blindness, and visual awareness. Psychophysiology, 40(3), 423-429. 
Koivisto, M., Lähteenmäki, M., Sørensen, T. A., Vangkilde, S., Overgaard, M., \& Revonsuo, A. (2008). The earliest electrophysiological correlate of visual awareness? Brain and Cognition, 66(1), 91-103.

Koivisto, M., \& Revonsuo, A. (2007). Electrophysiological correlates of visual consciousness and selective attention. NeuroReport, 18(8), 753-756.

Koivisto, M., Revonsuo, A., \& Salminen, N. (2005). Independence of visual awareness from attention at early processing stages. NeuroReport, 16(8), 817-821.

Laureys, S., Celesia, G. G., Cohadon, F., Lavrijsen, J., León-Carrión, J., Sannita, W. G., Sazbon, L., Schmutzhard, E., von Wild, K. R., Zeman, A., Dolce, G., \& the European Task Force on Disorders of Consciousness. (2010). Unresponsive wakefulness syndrome: A new name for the vegetative state or apallic syndrome. BMC Medicine, 8(1), 68.

Lamme, V. A. F. (2018). Challenges for theories of consciousness: Seeing or knowing, the missing ingredient and how to deal with panpsychism. Philosophical Transactions of the Royal Society B: Biological Sciences, 373, 20170344.

Lamy, D., Salti, M., \& Bar-Haim, Y. (2008). Neural correlates of subjective awareness and unconscious processing: An ERP study. Journal of Cognitive Neuroscience, 21(7), 14351446.

Li, R., Song, W.-Q., Du, J.-B., Huo, S., \& Shan, G.-X. (2015). Connecting the P300 to the diagnosis and prognosis of unconscious patients. Neural Regeneration Research, 10(3), 473480 .

Liu, Y., Paradis, A.-L., Yahia-Cherif, L., \& Tallon-Baudry, C. (2012). Activity in the lateral occipital cortex between 200 and $300 \mathrm{~ms}$ distinguishes between physically identical seen and unseen stimuli. Frontiers in Human Neuroscience, 6.

Luck, S. J. (2014). An introduction to the event-related potential technique (2nd ed.). The MIT Press.

Luck, S. J., Vogel, E. K., \& Shapiro, K. L. (1996). Word meanings can be accessed but not reported during the attentional blink. Nature, 383, 616-618.

Mashour, G. A., Roelfsema, P., Changeux, J.-P., \& Dehaene, S. (2020). Conscious processing and the global neuronal workspace hypothesis. Neuron, 105(5), 776-798.

Mazzi, C., Mazzeo, G., \& Savazzi, S. (2020). Late positivity does not meet the criteria to be considered a proper neural correlate of perceptual awareness. Frontiers in Systems Neuroscience, 14, 36.

Melloni, L., Schwiedrzik, C. M., Müller, N., Rodriguez, E., \& Singer, W. (2011). Expectations change the signatures and timing of electrophysiological correlates of perceptual awareness. Journal of Neuroscience, 31(4), 1386-1396. 
Näätänen, R., Kujala, T., \& Winkler, I. (2011). Auditory processing that leads to conscious perception: A unique window to central auditory processing opened by the mismatch negativity and related responses. Psychophysiology, 48(1), 4-22.

Naccache, L., Marti, S., Sitt, J. D., Trübutschek, D., \& Berkovitch, L. (2016). Why the P3b is still a plausible correlate of conscious access? A commentary on Silverstein et al., 2015. Cortex, 85, 126-128.

Nani, A., Manuello, J., Mancuso, L., Liloia, D., Costa, T., \& Cauda, F. (2019). The neural correlates of consciousness and attention: Two sister processes of the brain. Frontiers in Neuroscience, 13 .

Navajas, J., Ahmadi, M., \& Quian Quiroga, R. (2013). Uncovering the mechanisms of conscious face perception: A single-trial study of the N170 responses. The Journal of Neuroscience: The Official Journal of the Society for Neuroscience, 33(4), 1337-1343.

Öğmen, H., \& Breitmeyer, B. G. (Eds.). (2006). The first half second: The microgenesis and temporal dynamics of unconscious and conscious visual processes. MIT Press.

Ojanen, V., Revonsuo, A., \& Sams, M. (2003). Visual awareness of low-contrast stimuli is reflected in event-related brain potentials. Psychophysiology, 40(2), 192-197.

Pegna, A. J., Landis, T., \& Khateb, A. (2008). Electrophysiological evidence for early nonconscious processing of fearful facial expressions. International Journal of Psychophysiology, 70(2), 127-136.

Perrin, F., Schnakers, C., Schabus, M., Degueldre, C., Goldman, S., Brédart, S., Faymonville, M.-E., Lamy, M., Moonen, G., Luxen, A., Maquet, P., \& Laureys, S. (2006). Brain response to one's own name in vegetative state, minimally conscious state, and locked-in syndrome. Archives of Neurology, 63(4), 562-569.

Pitts, M.A., Lutsyshyna, L.A. and Hillyard, S.A., 2018. The relationship between attention and consciousness: an expanded taxonomy and implications for 'no-report' paradigms. Philosophical Transactions of the Royal Society B: Biological Sciences, 373, 20170348.

Pitts, M. A., Martínez, A., \& Hillyard, S. A. (2012). Visual processing of contour patterns under conditions of inattentional blindness. Journal of Cognitive Neuroscience, 24(2), 287-303.

Pitts, M. A., Metzler, S., \& Hillyard, S. A. (2014a). Isolating neural correlates of conscious perception from neural correlates of reporting one's perception. Frontiers in Psychology, 5.

Pitts, M. A., Padwal, J., Fennelly, D., Martínez, A., \& Hillyard, S. A. (2014b). Gamma band activity and the $\mathrm{P} 3$ reflect post-perceptual processes, not visual awareness. NeuroImage, 101, $337-350$. 
Polich, J. (2007). Updating P300: An integrative theory of P3a and P3b. Clinical Neurophysiology: Official Journal of the International Federation of Clinical Neurophysiology, 118(10), 2128-2148.

Polich, J. (Ed.) (2020). 50+ Years of P300: Where are we now. Psychophysiology, 57(7).

Robitaille, N., \& Jolicoeur, P. (2006). Fundamental properties of the N2pc as an index of spatial attention: Effects of masking. Canadian Journal of Experimental Psychology/Revue Canadienne de Psychologie Expérimentale, 60(2), 101-111.

Rohaut, B., Alario, F.-X., Meadow, J., Cohen, L., \& Naccache, L. (2016). Unconscious semantic processing of polysemous words is not automatic. Neuroscience of Consciousness, 2016(1), niw010.

Rohaut, B., Faugeras, F., Chausson, N., King, J.-R., Karoui, I. E., Cohen, L., \& Naccache, L. (2015). Probing ERP correlates of verbal semantic processing in patients with impaired consciousness. Neuropsychologia, 66, 279-292.

Rutiku, R., Aru, J., \& Bachmann, T. (2016). General markers of conscious visual perception and their timing. Frontiers in Human Neuroscience, 10.

Rutiku, R., Martin, M., Bachmann, T., \& Aru, J. (2015). Does the P300 reflect conscious perception or its consequences? Neuroscience, 298, 180-189.

Salti, M., Bar-Haim, Y., \& Lamy, D. (2012). The P3 component of the ERP reflects conscious perception, not confidence. Consciousness and Cognition, 21(2), 961-968.

Sanchez, G., Hartmann, T., Fuscà, M., Demarchi, G., \& Weisz, N. (2020). Decoding across sensory modalities reveals common supramodal signatures of conscious perception. Proceedings of the National Academy of Sciences, 117(13), 7437-7446.

Sandberg, K., Bahrami, B., Kanai, R., Barnes, G. R., Overgaard, M., \& Rees, G. (2013). Early visual responses predict conscious face perception within and between subjects during binocular rivalry. Journal of Cognitive Neuroscience, 25(6), 969-985.

Sandberg, K., Barnes, G. R., Bahrami, B., Kanai, R., Overgaard, M., \& Rees, G. (2014). Distinct MEG correlates of conscious experience, perceptual reversals and stabilization during binocular rivalry. NeuroImage, 100, 161-175.

Schankin, A., Hagemann, D., \& Wascher, E. (2009). The N2pc as an electrophysiological correlate of attention in change blindness. Journal of Psychophysiology, 23(2), 43-51.

Schelonka, K., Graulty, C., Canseco-Gonzalez, E., \& Pitts, M. A. (2017). ERP signatures of conscious and unconscious word and letter perception in an inattentional blindness paradigm. Consciousness and Cognition, 54, 56-71.

Schlossmacher, I., Dellert, T., Bruchmann, M., \& Straube, T. (2021). Dissociating neural correlates of consciousness and task relevance during auditory processing. NeuroImage, 228. 
Schlossmacher, I., Dellert, T., Pitts, M., Bruchmann, M., \& Straube, T. (2020). Differential effects of awareness and task relevance on early and late ERPs in a no-report visual oddball paradigm. Journal of Neuroscience, 40(14), 2906-2913.

Schoenle, P. W., \& Witzke, W. (2004). How vegetative is the vegetative state? Preserved semantic processing in VS patients - Evidence from N400 event-related potentials. NeuroRehabilitation, 19(4), 329-334.

Schröder, P., Nierhaus, T., \& Blankenburg, F. (2020). Late cortical potentials are not a reliable marker of somatosensory awareness. BioRxiv, 2020.10.01.322651.

Schröder, P., Schmidt, T. T., \& Blankenburg, F. (2019). Neural basis of somatosensory target detection independent of uncertainty, relevance, and reports. ELife, 8, e43410.

Schubert, T. M., Rothlein, D., Brothers, T., Coderre, E. L., Ledoux, K., Gordon, B., \& McCloskey, M. (2020). Lack of awareness despite complex visual processing: Evidence from event-related potentials in a case of selective metamorphopsia. Proceedings of the National Academy of Sciences, 117(27), 16055-16064.

Scrivener, C. L., Malik, A., Marsh, J., Lindner, M., \& Roesch, E. B. (2019). An EEG study of detection without localisation in change blindness. Experimental Brain Research, 237(10), 2535-2547.

Sekar, K., Findley, W. M., Poeppel, D., \& Llinás, R. R. (2013). Cortical response tracking the conscious experience of threshold duration visual stimuli indicates visual perception is all or none. Proceedings of the National Academy of Sciences, 110(14), 5642-5647.

Sergent, C., Baillet, S., \& Dehaene, S. (2005). Timing of the brain events underlying access to consciousness during the attentional blink. Nature Neuroscience, 8(10), 1391-1400.

Shafto, J. P., \& Pitts, M. A. (2015). Neural signatures of conscious face perception in an inattentional blindness paradigm. Journal of Neuroscience, 35(31), 10940-10948.

Siclari, F., Baird, B., Perogamvros, L., Bernardi, G., LaRocque, J. J., Riedner, B., Boly, M., Postle, B. R., \& Tononi, G. (2017). The neural correlates of dreaming. Nature Neuroscience, 20(6), 872-878.

Siegle, J. H., Jia, X., Durand, S., Gale, S., Bennett, C., Graddis, N., Heller, G., Ramirez, T. K., Choi, H., Luviano, J. A., Groblewski, P. A., Ahmed, R., Arkhipov, A., Bernard, A., Billeh, Y. N., Brown, D., Buice, M. A., Cain, N., Caldejon, S., ... Koch, C. (2021). Survey of spiking in the mouse visual system reveals functional hierarchy. Nature, 1-7.

Silverstein, B. H., Snodgrass, M., Shevrin, H., \& Kushwaha, R. (2015). P3b, consciousness, and complex unconscious processing. Cortex, 73, 216-227.

Sitt, J. D., King, J.-R., El Karoui, I., Rohaut, B., Faugeras, F., Gramfort, A., Cohen, L., Sigman, M., Dehaene, S., \& Naccache, L. (2014). Large scale screening of neural signatures of 
consciousness in patients in a vegetative or minimally conscious state. Brain: A Journal of Neurology, 137(8), 2258-2270.

Sterzer, P., Jalkanen, L., \& Rees, G. (2009). Electromagnetic responses to invisible face stimuli during binocular suppression. NeuroImage, 46(3), 803-808.

Strauss, M., Sitt, J. D., King, J.-R., Elbaz, M., Azizi, L., Buiatti, M., Naccache, L., van Wassenhove, V., \& Dehaene, S. (2015). Disruption of hierarchical predictive coding during sleep. Proceedings of the National Academy of Sciences, 112(11), E1353-E1362.

Sutton, S., Braren, M., Zubin, J., \& John, E. R. (1965). Evoked-potential correlates of stimulus uncertainty. Science, 150, 1187-1188.

Suzuki, M., \& Noguchi, Y. (2013). Reversal of the face-inversion effect in N170 under unconscious visual processing. Neuropsychologia, 51(3), 400-409.

Tagliabue, C. F., Mazzi, C., Bagattini, C., \& Savazzi, S. (2016). Early local activity in temporal areas reflects graded content of visual perception. Frontiers in Psychology, 7.

Travis, S. L., Dux, P. E., \& Mattingley, J. B. (2019). Neural correlates of goal-directed enhancement and suppression of visual stimuli in the absence of conscious perception. Attention, Perception, and Psychophysics, 81(5), 1346-1364.

Tsuchiya, N., Wilke, M., Frässle, S., \& Lamme, V. A. F. (2015). No-report paradigms: Extracting the true neural correlates of consciousness. Trends in Cognitive Sciences, 19(12), 757-770.

Tzovara, A., Simonin, A., Oddo, M., Rossetti, A. O., \& De Lucia, M. (2015). Neural detection of complex sound sequences in the absence of consciousness. Brain: A Journal of Neurology, 138(5), 1160-1166.

van Gaal, S., Naccache, L., Meuwese, J. D. I., van Loon, A. M., Leighton, A. H., Cohen, L., \& Dehaene, S. (2014). Can the meaning of multiple words be integrated unconsciously? Philosophical Transactions of the Royal Society B: Biological Sciences, 369.

Verleger, R. (2020). Effects of relevance and response frequency on P3b amplitudes: Review of findings and comparison of hypotheses about the process reflected by P3b.

Psychophysiology, 57(7), e13542.

Verleger, R., \& Jaśkowski, P. (2008). Disentangling neural processing of masked and masking stimulus by means of event-related contralateral-ipsilateral differences of EEG potentials. Advances in Cognitive Psychology, 3(1-2), 193-210.

Wang, X.-Y., Wu, H.-Y., Lu, H.-T., Huang, T.-T., Zhang, H., \& Zhang, T. (2017). Assessment of mismatch negativity and P300 response in patients with disorders of consciousness. European Review for Medical and Pharmacological Sciences, 21(21), 4896-4906. 
Wiegand, K., \& Gutschalk, A. (2012). Correlates of perceptual awareness in human primary auditory cortex revealed by an informational masking experiment. NeuroImage, 61(1), 6269.

Wilenius-Emet, M., Revonsuo, A., \& Ojanen, V. (2004). An electrophysiological correlate of human visual awareness. Neuroscience Letters, 354(1), 38-41.

Woodman, G. F., \& Luck, S. J. (2003). Dissociations among attention, perception, and awareness during object-substitution masking. Psychological Science, 14(6), 605-611.

Wyart, V., Dehaene, S., \& Tallon-Baudry, C. (2012). Early dissociation between neural signatures of endogenous spatial attention and perceptual awareness during visual masking. Frontiers in Human Neuroscience, 6.

Ye, M., \& Lyu, Y. (2019). Later positivity reflects post-perceptual processes: Evidence from immediate detection and delayed detection tasks. Frontiers in Psychology, 10. 